\title{
ПОТЕНЦИАЛЫ ИОНИЗАЦИИ НЕПРЕДЕЛЬНЫХ УГЛЕВОДОРОДОВ
}

\section{3. Нормальные алкины $\mathrm{C}_{8}-\mathrm{C}_{14}$}

Silvia RANG, E. MARTINSON. KULLASTUMATA SUSIVESINIKE IONISATSIOONI POTENTSIAALID. 3. $n$-ALKOONID $\mathrm{C}_{8}-\mathrm{C}_{14}$

Silvia RANG, E. MARTINSON. IONIZATION POTENTIALS OF UNSATURATED HYDROCARBONS. 3. $n$-ALKYNES $\mathrm{C}_{8}-\mathrm{C}_{14}$

В гомологическом ряду $\boldsymbol{H}$-алкинов ранее изучены низшие члены до $\mathrm{C}_{8}-2$ - и 3-нонины, 3- и 5-децины, 6-додецин и 7-тетрадецин $\left[{ }^{1-4}\right]$. В данной работе исследованы высшие изомеры $\mathrm{C}_{8}-\mathrm{C}_{14}$ (табл. 1).

Как следует из данных табл. 1, потенциалы ионизации (ПИ) н-алкинов определяются главным образом степенью замещения при тройной связи, меньшее влияние на ПИ оказывают длина заместителя и число атомов углерода в молекуле $(n)$. Удлинение углеродной цепи от $\mathrm{C}_{8}$ до $\mathrm{C}_{10}$ (при данном положении тройной связи) приводит к весьма незначительному $(0,05$ эв) уменьшению ПИ $\mu$-алкинов. ПИ $\boldsymbol{H}$-алкинов выше $\mathrm{C}_{10}$ практически независимы от $n$.

Таблица 1

Первые адиабатические ПИ $н$-алкинов $\mathrm{C}_{8}-\mathrm{C}_{14}$, эв

\begin{tabular}{|c|c|c|c|c|c|c|c|}
\hline \multirow{2}{*}{$\begin{array}{l}\text { Соеди- } \\
\text { нения }\end{array}$} & \multicolumn{7}{|c|}{ Положение тройной связи } \\
\hline & 1 & 2 & 3 & 4 & 5 & 6 & 7 \\
\hline $\begin{array}{l}\text { Октины } \\
\text { Нонины } \\
\text { Децины } \\
\text { Ундецины } \\
\text { Додецины } \\
\text { Тридецины } \\
\text { Тетра- }\end{array}$ & $\begin{array}{l}9,95 \\
9,93 \\
9,91 \\
9,90 \\
9,90 \\
9,90\end{array}$ & $\begin{array}{l}9,31 \\
9,32 \\
9,30 \\
9,28 \\
9,29 \\
9,28\end{array}$ & $\begin{array}{c}9,22 \\
9,20 \\
9,19 \\
9,17 \\
9,17 \\
9,14 \pm 0,03\end{array}$ & $\begin{array}{c}9,20 \\
9,17 \pm 0,03 \\
9,17 \\
9,13 \\
9,14 \pm 0,03 \\
9,07 \pm 0,03\end{array}$ & $\begin{array}{c}9,14 \\
9,11 \\
9,09 \pm 0,03 \\
9,09 \pm 0,03\end{array}$ & $\begin{array}{c}9,06 \pm 0,03 \\
9,05\end{array}$ & 20 \\
\hline децины & 9,89 & $9,26 \pm 0,03$ & 9,17 & $9,11 \pm 0,03$ & $9,10 \pm 0,03$ & $9,09 \pm 0,02$ & $9,03 \pm 0,04$ \\
\hline
\end{tabular}

Погрешность измерения $\pm 0,02$ эв, если не обозначено иначе. Литературные данные

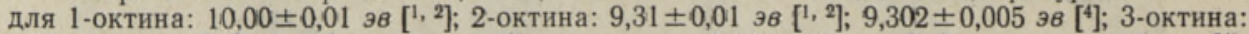
$9,23 \pm 0,01$ эв [1, $\left.{ }^{1}\right], 9,222 \pm 0,005$ эв [ $\left.{ }^{4}\right] ; 4$-октина: $9,20 \pm 0,01$ эв [1, 2$], 9,196 \pm 0,005$ эв [4]; 2 -нонина: 9,289 $\pm 0,005$ эв [ [4]; 3-нонина: 9,202 $\pm 0,005$ эв [4]; 3-децина: $9,190 \pm 0,005$ эв [4];

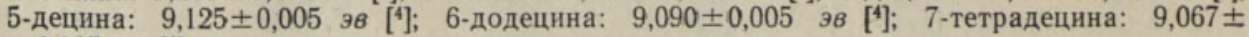
$\pm 0,005$ эв [4]. 
Снижение ПИ н-алкинов при перемещении тройной связи к центру молекулы (средние значения для $\mathrm{C}_{4}-\mathrm{C}_{14}$ ), эв

Положение тройной связи в молекуле

\begin{tabular}{l|l|l|l|l|l}
\hline $1 \rightarrow 2$ & $2 \rightarrow 3$ & $3 \rightarrow 4$ & $4 \rightarrow 5$ & $5 \rightarrow 6$ & $6 \rightarrow 7$ \\
\hline 0,62 & 0,11 & 0,04 & 0,02 & 0,03 & $0,02-0,04$
\end{tabular}

По мере перемещения тройной связи. к центру молекулы ПИ $\boldsymbol{H}$-алкинов уменьшаются (табл. 1), величины спада при этих переходах убывают в таком же порядке (табл. 2). Наивысшими значениями ПИ $(9,89-$ 9,95 эв) обладают 1-алкины. Замещение водорода у углерода тройной связи метильным радикалом (переход от 1-алкинов к 2-алкинам, т. е. от монозамещенных ацетиленов к двухзамещенным) приводит к наибольшему снижению. ПИ $(0,62$ әв). Это обусловлено бо́льшим индукционным влиянием метильной группы. Введение этильного радикала вместо метильного (переход от 2-алкинов к 3-алкинам) обусловливает значительно меньшее снижение ПИ $(0,11$ эв). Для остальных переходов (от 3-алкинов к 4-алкинам и т. д., см. табл. 2) характерны весьма незначительные и близкие величины снижения ПИ $(0,02-0,04$ эв). Приведенные результаты согласуются с известными закономерностями уменьшения ПИ при увеличении симметрии молекул и числа алкильных заместителей у кратной связи $\left[{ }^{5-7}\right]$. Электронодонорные алкильные группы увеличивают электронную плотность при кратной связи, способствуют лучшей компенсации электронного дефицита в ионе, увеличивают его стабильность и приводят к понижению ПИ молекулы. При равных $n$ и положении кратной связи в молекуле ПИ н-алкенов ниже [8], чем ПИ $H$-алкинов, что свидетельствует о более легкой ионизации $н$-алкенов. Этим и обусловлена более высокая по сравнению с $H$-алкинами (тройной связи) реакционная способность $н$-алкенов (двойной углеродуглеродной связи) по отношению к электрофильным реагентам.

Методика работы описана в $\left[^{8}\right]$.

\section{Л И ТЕРА Т Р РА}

1. Гурвич Л. В., Карачевцев Г. В., Кондратвев В. Н., Лебедев Ю. А., Медв едев В. А., Пот а пов В. К., Ходе ев Ю. С., Энергии разрыва хнмических связей. Потенциалы ионизации и сродство к электрону, М., 1974.

2. Ви ллем Я. Я., Пи к в е р Р. И., С ак с О. В., Мат. III Всесоюз. конф. по спектроскопии вакуумного ультрафиолета и взаимодействию излучения с веществом, Харьков, 1972.

3. В и лесо в Ф. И., Успехи фотоники, сб. 1, 5 (1969).

4. Carlier, P., Dubois, J. E., Masclet, P., Mouvier, G., J. Electron Spectrosc. and Related Phenomena, 7, 55 (1975).

5. Полякова А. А., Х мельн ицкий Р. А., Введение-в масс-спектрометрию органических соединений, М.-Л., 1966.

6. De me o, D. A., E1-S a ye d, M. A., J. Chem. Phys., 52, 2622 (1970).

7. Masclet, P., Grosjean, D., Mouvier, G., Dubois, J., J. Electron Spectrosc. and Related Phenomena, 2, 225 (1973).

8. Р анг С., М яртинсон Э., М юр и сепп М., Изв. АН Эст. ССР, Хим. Геол., 23, 352 (1974).

Институт химии

Академии наук Эстонской ССР
Поступила в редакцию 1/VII 1976 